\title{
Behavior and Informal Learning at Night in a 24 Hour Space: A Case Study of the Hong Kong Design Institute Library
}

\author{
Terry Yip, Dickson K.W. Chiu, The University of Hong Kong \\ Allan Cho, University of British Columbia Library \\ Patrick Lo, University of Tsukuba
}

\begin{abstract}
This study explores the night activities of Hong Kong Design Institute (HKDI) students in Zone24, a 24hour opening learning space managed by HKDI Learning Resources Centre (LRC), also referred to as the Library. The purpose of this study is to evaluate the effectiveness of 24-hour learning space. Qualitative research will be conducted to identify and compare the students' behaviors between daytime and night in Zone24. In addition, this study investigates how overnight opening of the learning space facilitates the learning. The result of this study allows the librarians or administrators to have better understanding on the students' needs at night in a 24-hour learning space so that the improvement actions could be implemented effectively.
\end{abstract}

\section{Introduction}

Academic libraries across the world have adopted new kinds of learning spaces with such facilities as counter services, information technology equipment, and furniture. Such new learning spaces have becomes a gathering places intended for students to collaborate on projects and learn together. Often referred to as a learning commons or information commons, some of these spaces offer 24-hour opening. Established in 2007, the Hong Kong Design Institute (HKDI) established Zone24 that functions like a learning or information commons. Along with the HKDI Library, Zone24 is a key part of the Learning Resources Centre (LRC). As a space for students who study, hold discussions, and collaborate on projects late into the evening and overnight, there are great opportunities in better understanding the learning behaviors of students in such a unique environment. In this paper, we intend to examine the following themes: 
- Why do students choose to use Zone24 in particular at night?

- What are the similarities and differences in student activities between daytime and nighttime?

- What particular needs do students have at night?

- What can 24-hour spaces such as Zone24 inform us about student learning?

Librarians, especially library managers, may not be able to have a detailed observation on the students' activities at late night since they are most probably on duty at that time. Moreover, we cannot fully digest the needs of the students through observation. It is significant that if the librarian knows the actual student behaviors and needs in a 24-hour learning space at night, they can adopt appropriate enhancements in terms of services, facilities, and rules.

\section{Literature review}

According to the survey about learning commons of Donkai, Toshimori, and Mizoue (2011), over 60\% of the learning commons in Japan were established in the latter half of 2010s. This means that learning commons have been rapidly expanding. Hong Kong Design Institute (HKDI) also established Zone24 in 2010.

\section{4-hour Library Spaces}

Although the adoption of 24-hour all-night spaces is still a relatively new phenomenon, it is well documented in the literature and has largely brought positive changes to libraries. In examining a pilot project to extend to 24-hour services at the University of Denver Library, Sewell (2013) reported that students appreciated the effort, and it made a real impact on their lives. As one of many recent initiatives to make the library a more welcoming space and to respond to student requests over the past years, the effort to provide 24-hour access to the library shows how library staff members from several departments provided quality services and had gone beyond their established duties than any other single effort of the library.

In a study of student activities between the hours of midnight and 2 a.m., Lawrence and Weber (2012) found that patrons viewed the library as a quiet, peaceful place conducive to study and placed high value on late night access to the library so much that students requested further extension of the late-night 
hours in addition to offering access to more library space. The research discovered the library as a haven required by a dedicated group of students who greatly needed a late-night place to work in.

At the Bizzell Memorial Library from the University of Oklahoma, Engel, Womack, and Ellis (2002) conducted a questionnaire about library opening hours and found that $70.3 \%$ of the respondents typically used the library between 10:00pm and 12:00 midnight, which surprisingly was the highest typically usage. But what this particular study did not touch on the "commons" study space, but rather the library in general. Therefore, we may not fully understand the behaviors of the students in a dedicated 24-hour learning space at night, which our study hopes to achieve.

\section{The Commons concept}

The commons as a learning space has been firmly established for collaborative and informal learning in most academic and school libraries. For example, Lippincott and Greenwell (2011) comment that learning commons and information commons are often spaces for full-service learning, research, and project coordination for students. It often serves a collaborative space for doing course assignments and area for group meetings with the learning commons providing tools and resources to support creative efforts, in addition to on-site staff specialists provide help as needed. In particular, Bennett (2003) points to the social benefits of learning commons. Learning commons bring people together, not around informally shared interests as happens in traditional common rooms, but around shared learning tasks, sometimes formalized in class assignments. The core activity of learning commons would not be the manipulation and mastery of information as in information commons, but the collaborative learning by which students turn information into knowledge and sometimes even into wisdom. Learning commons "should be built around the social dimensions of learning and knowledge and managed by students themselves for learning purposes that vary greatly and change frequently.” (Bennett, 2003, p. 38)

Sinclair (2007) names "Commons 2.0" as a physical space that provides wireless communication and flexible workspace cluster to facilitate interaction and collaboration. In addition, the space should be comfortable in making users feel relaxed, encourage creativity, and support peer learning.

\section{Importance of Learning Spaces in a Commons}

Donkai et al. (2011) describe that the learning styles of Net Generation college students, also called "digital natives," require high-quality visual technologies and collaborative working spaces, because 
such students favor intuitive visual communications and learn better through discovery than through being taught. Lizabeth (2004) similarly points out that todays' digital natives live in a collaborative world that did not exist a generation ago. Such natives use a lot of information technology and interactivity as a hallmark of their lives. Therefore, a "commons" area that is physically comfortable, aesthetically pleasing, and with readily available technologies such as Wi-Fi networks and computers are desirable places for students working on something together (Sinclair, 2007). In a survey of students at the Chinese University of Hong Kong (CUHK), Kwong, Ho, Lam, \& Leung (2011) revealed that convenience of locations is the key advantage of why students prefer the library over other locations on the university’s campus.

However, what the literature seems particularly lacking is an examination into student learning behaviors and information needs in the learning commons late into the evenings and overnight periods. Our research intends to contribute to the research literature about this important understanding of student learning in a 24-hour learning space managed by an academic library.

\section{Methodology}

This study used a qualitative research method in which four groups of students were interviewed. With two to three HKDI students participating in each group, the interviews were conducted in Zone24 in late evening. Convenience sampling was selected because the target interviewees are Zone24 student users and this approach eliminates the students who never used Zone24 at night. The comments and experiences related to Zone24 especially activities at night would be asked. The questions to students mainly cover the following areas:

- The time that they usually stay in Zone24

- The daytime and night activities in Zone24

- The reasons of staying in Zone24 at night

- The experience on using other learning spaces

- The facilities and services are used in Zone24 at night.

- Their information needs at night

- The issues and special experiences encountered in Zone24 at night 


\section{Findings}

In this study, a total of 10 respondents participated in the four-round interviews. All the participants are higher diploma students who are taking design-related or multimedia programs. The analysis is organized into three main areas: (1) the reasons why HKDI students choose Zone24 for their night learning activities, (2) the comparison between their daytime and night activities, and (3) their special needs at night in Zone24.

\section{Reasons for Choosing Zone24 at Night}

Table 1: Reasons of Students Choosing Zone24 at Night

\begin{tabular}{|l|l|}
\hline Criteria & Reasons \\
\hline Opening Hours & $\begin{array}{l}\bullet \text { Zone24 is the only 24-hour opening learning space } \\
\text { in campus. } \\
\bullet\end{array}$ \\
\hline Facilities & $\begin{array}{l}\text { Students have lessons at daytime. They do not have } \\
\text { sufficient time to finish their projects at daytime. } \\
\text { Therefore, they complete their projects at night. }\end{array}$ \\
& $\begin{array}{l}\text { Z Zone24 provides the facilities to support learning } \\
\text { activities and design works. The facilities include: } \\
\text { o Computers (including iMac) } \\
\text { o Professional software } \\
\text { o Wi-Fi network } \\
\text { o Power sockets } \\
\text { o Color all-in-one photocopier } \\
\text { o Sufficient lighting }\end{array}$ \\
\hline Location & $\begin{array}{l}\text { The location of Zone24 is convenient for moving } \\
\text { the physical model and tools because it is near the } \\
\text { lockers and projects submission area. }\end{array}$ \\
& $\begin{array}{l}\text { Zone24 is near the classrooms. Students come to } \\
\text { Zone24 after class. }\end{array}$ \\
\hline Design-friendly & $\begin{array}{l}\text { Zone24 welcomes students to conduct the design } \\
\text { activities. Design works may not be welcomed in } \\
\text { Environment }\end{array}$ \\
\hline
\end{tabular}

From the interviews, a number of reasons (as summarized in Table 1) were identified for why HKDI students chose Zone24 for their learning activities at night. There were a number variables including the opening hours of various areas, learning facilities support, location, and the support of their design activities.

\section{Opening Hours}


24-hour opening learning space is a key advantage according to the respondents. This is unsurprising since other learning spaces (such as classrooms, computer labs, and design studios) on campus are unavailable overnight or even at nighttime. HKDI students have high demands on the learning space at nighttime.

As classes at HKDI tend to occur during the day, most students are pressed for time during the day to work on projects and instead rely on evenings and late night for their work. Most go to Zone24 after classes at about 5:30pm - 6:00pm and usually leave before the last bus or last train. The remaining students who cannot finish by then mostly decide to stay overnight in Zone24 for convenience.

Although the Library has computer facilities, tables, chairs, various printed and electronic resources, and group study rooms also offers longer hours than other areas on campus, the Library is not open overnight. For students who decide to study after the Library is close, especially near the end of the semester, respondents revealed that Zone24 is their preferred learning space on campus.

As classrooms and design studios are closed in the evenings, Zone24 is a desirable choice for students to work on their projects and creative works at night. In a study on the HKDI Library, when the studio is closed and the students suddenly feel the need to fulfill their creative urges, and wishes to do a painting, they would lay out the materials on the table inside the Library and start painting (Lo \& Chiu, 2014). This behavior is very common among respondents' views of Zone24.

\section{Facilities to support learning}

Zone24 provides various facilities to support the learning for student. As tables and chairs are the basic facilities for students to engage in artwork creation and discussion, the furniture is arranged for group seating to enable better collaboration and interaction. In addition to those basic facilities, up-to-date information technology (IT) facilities are critical elements for students. Therefore, Zone24 provides computers, Wi-Fi network and all-in-one photocopier to support their learning activities, such as working on the projects and searching information. With the combination of the facilities and 24-hour opening, their learning activities are highly supported at night.

A respondent who is studying a multimedia program mentions that the iMac computers and professional software are important for him: 
Student G: Zone24 provides a space for us to do homework overnight. Furthermore, Zone24 offers iMac and specific software to help with our homework. iMac is expensive for us and I don't have one at home.

Notebooks, tablets, and smartphone devices are popular nowadays. Some students bring their own devices to the campus. Students use them for their projects and creative production. In addition, they use their devices to find inspiration and search other information from the Internet via the campus Wi-Fi. A recent study by Lo \& Chu (2015) found that the Internet was the most favored medium for finding inspiration amongst the student respondents at HKDI, implying that Wi-Fi is an important tool for students to access the Internet using such devices. As Zone24 has full coverage of Wi-Fi network, students can access information anytime and anywhere. Zone24 also has power sockets installed for the continuous use of their devices. A respondent comments on their usage of Wi-Fi and portable devices in Zone24.

Student H: I bring my own notebook for my projects in Zone24. I use the Zone24 Wi-Fi or LAN port to submit my homework online and search the information from the Internet. But I have also used Zone24 desktop to submit my homework as well.

The color all-in-one photocopier allows students to print their homework and is a critical service since it is the only place to provide printing at midnight on campus.

Student B: We often use printer (in Zone24). It is because only Zone24 offers printer for us at night. The printer is quite helpful in printing our homework.

A student respondent highlights that, Zone24 provides adequate lighting to support nighttime activities. It is particularly important for design students to create their models, posters, and other design works. A respondent with another interpretation about the lighting at night, discloses,

Student F: Appropriate lighting is important. This bright learning space increases my concentration and boosts my energy.

When the Library is closed, only Zone24 and outdoor spaces are available at nighttime. But compared to Zone24, which provides comfortable air-conditioned space in addition to lighting, outdoor areas are not 
desirable learning spaces at night because they have insufficient lighting and has mosquito problems according to the respondents.

\section{Location}

The convenient location of Zone24 is another key reason why students prefer to use it for their nighttime activities. Situated near the institute’s classrooms, students in particular often enter Zone24 almost immediately after class. Moreover, since Zone24 intersects between HKDI and the Institute of Vocational Education (IVE) Lee Wai Lee campus, Zone24 is considered central node on campus. Since design students are often required to submit physical models of their projects, they would usually store their physical models, raw materials, and tools in their lockers near Zone24. Afterwards, they would conveniently take it away from the locker and continue their work in Zone24. After they finish their project overnight, they can submit their project at the nearby area to reduce the potential damage of the physical model. A respondent highlights the importance of the convenient location for design students:

\section{[insert photo here]}

Student J: Since the output of our projects is to produce physical models instead of reports, it is not convenient to carry around our projects from far away. Zone24 is inside the campus and near the submission area.

\section{Design-friendly Environment}

Since HKDI offers a number of design programs, some projects require a certain amount of arts and crafts, such as cutting and pasting paper onto cardboards. Some students bring their own sewing machines in order to complete their fashion design homework. Many places on (and off) campus may not welcome such design activities since they require a lot of space and produce much garbage. However, Zone24 encourages students to do their craftsmanship. A stage and set design student has the following response:

Student J: Zone24 allows discussion, cutting, and pasting. It is not suitable to do so in McDonalds.

To summarize, Zone24 is a unique learning space designed for design students with night and even overnight learning support. HKDI students like staying in Zone24 at night because of the combination of several reasons described above. 


\section{Comparison between night and daytime behaviors}

Table 2: Comparison of major behaviors between night and daytime

\begin{tabular}{|c|c|}
\hline \multicolumn{2}{|l|}{ Similarity } \\
\hline $\begin{array}{l}\text { Collaborative Project-Based } \\
\text { Learning }\end{array}$ & $\begin{array}{l}\text { - Student activities are related to their project } \\
\text { assignments whether daytime or night. } \\
\text { - Students learn from their peers via project } \\
\text { discussion and interaction. }\end{array}$ \\
\hline \multicolumn{2}{|l|}{ Differences } \\
\hline Short Sleep & $\begin{array}{l}\text { - In contrast to daytime, taking naps is relatively } \\
\text { common at night in Zone24. The reasons include: } \\
\text { o They stay in Zone24 for long periods at night } \\
\text { o The have alternative place (e.g. library) that } \\
\text { provides more sofas for short sleep at daytime. }\end{array}$ \\
\hline Eating Behavior & $\begin{array}{l}\text { - Eating is more common at night in Zone24. The } \\
\text { reasons include: } \\
\text { o They wish to gain time for catching up the } \\
\text { progress of their projects. } \\
\text { o Many restaurants or stores are closed at } \\
\text { midnight. }\end{array}$ \\
\hline
\end{tabular}

In this section, we compare the student behaviors between daytime and nighttime, as summarized in

Table 2. The key similarity is that the students use Zone24 for learning purpose. However, the differences should be more focused because it is particularly useful to understand students' special needs at night.

\section{Collaborative Project-Based Learning}

All respondents report that the key activities of students in Zone24 are related to learning at any time day or night. They highlighted that they spent most of their time in doing projects and collaborating with their peers. They preferred to do their projects together and exchange their ideas on their projects while learning from their peers via discussion and interaction. Collaborative project-based learning is an innovative approach to engage students in a project. Students drive their own learning through deep collaboration on projects (Bell, 2010; Lee, Huh, \& Reigeluth, 2015). This approach has effectively motive students to learning through their projects regardless of daytime or nighttime.

\section{Short Sleep}

Sleep is an essential physiological needs of most people (McLeod, 2014). When they stay in Zone24 at night and even overnight, students often feel tired and sleepy. After a day of classes and deep 
concentration on their projects, dozing off in their seats is inevitability for students. One respondent mentioned that she had never taken a nap in Zone24 at daytime but she often napped there at night. Another respondent even saw other students bring their own sleeping bags for use in Zone24. Such students often stay in Zone24 for long periods at night. Hence, taking naps is a common phenomenon in Zone24 at night.

\section{Eating Behavior}

Some students prefer to eat in Zone24 more than other areas when they work on projects at night. In contrast, during daytime, students have more opportunities to eat outside Zone24. The respondents explained:

Student J: Yes (I prefer eating outside the campus at daytime and eating inside Zone24 at night), I hope to gain time by eating there (Zone24) for catching up on my homework. The submission deadline of my homework is usually close to the evening time.

Student I: Yes, (I use the vending machines more frequently at night in particular) because many restaurants or stores are closed at midnight.

The explanation from student $\mathrm{J}$ implies that the pressure on the project progress is relatively higher at night. They eat in Zone24 to reduce the time for eating outside, thus to catch up and make progress on their work projects. In addition, many restaurants are not open overnight, therefore increasing the necessity to eat in Zone24 at night.

$<$ Table 2 about insert here>

\section{Students' special needs at night}

Table 3: Students' special needs in Zone24 at night

\begin{tabular}{|l|l|}
\hline Needs & Explanations \\
\hline Study Rooms & $\begin{array}{l}\text { Only the library provides study rooms, but the } \\
\text { library does not provide 24-hour opening. }\end{array}$ \\
& $\begin{array}{l}\text { - Multimedia major students use it for sound } \\
\text { recording. }\end{array}$ \\
& $\begin{array}{l}\text { - Some students need a silent space. } \\
\text { - Some students want to prevent other classmates }\end{array}$ \\
\hline
\end{tabular}




\begin{tabular}{|c|c|}
\hline & from overhearing their ideas on the projects. \\
\hline Printing Service & $\begin{array}{l}\text { - Zone24 is the only place providing printing service } \\
\text { after the library is closed. } \\
\text { - They use printers for their projects such as posters. }\end{array}$ \\
\hline $\begin{array}{l}\text { Design Tools (e.g. } \\
\text { stationery) }\end{array}$ & $\begin{array}{l}\text { - Design tools are required for their projects. But the } \\
\text { design studio and stationery stores are closed at } \\
\text { night. }\end{array}$ \\
\hline Food and Drinks & $\begin{array}{l}\text { - Variety in food and drinks of the vending machines } \\
\text { should be increased. } \\
\text { - Drinking fountains with hot water should be } \\
\text { offered. }\end{array}$ \\
\hline
\end{tabular}

Table 3 summarized the special needs of students in Zone24. Silent study space is actually an area that Zone24 lacks as a learning space. Since the key activities of many students in Zone24 are related to projects and collaborative learning, study rooms are necessary for students; yet Zone24 does not have such study rooms. The only time when students can use study rooms is before the closing of the Library. When asked about her needs in Zone24, a multimedia major student respondent expressed that since her project required sound recording, she needed a silent space such a study room in the Library. Another student, a fashion and image major, responded that she needed to have a study room for the group projects so that she can keep her ideas away from her classmates outside of her group. A study room, in her view, is an essential at night for students to do their projects in Zone24.

Printing is another key element for many design students. Although students have high demands on the printing service, Zone24 only provides one all-in-one photocopier. Students can still print their projects or posters after the library and studios are closed at night; as a consequence, the Zone24 printer is often busy during late evenings. When there are any technical problems with the printer, such as empty toner or paper tray, students have no alternative printer to continue their projects. Moreover, since design students need specific tools (such as cutting mats and cutters) for their design work, such students are out of luck as design studios and stationery stores are closed in the evenings. Thus, design tools and printers are in high demand for students to work on their projects when they stay in Zone24 at night.

As mentioned earlier, eating and drinking are common behaviors of students at night, and not surprisingly, vending machines are also in high demand at night. A number of respondents suggested an increase in the variety of food and drinks in addition to refilling the stock in the vending machines could 
improve the services at Zone24. One particular need was also interesting according to students: drinking fountains with hot water.

$<$ Table 3 about insert here $>$

\section{Discussions}

\section{Effectiveness on Students' Learning Support at Night}

According to feedback from student respondents, Zone24 achieves its purpose as a learning space and is able to support student learning especially during the night and overnight periods. As all student respondents indicate that their key activities in Zone24 are projects and discussion, they have high demands on this learning space not only at daytime, but also in the evening and overnight. Zone24 also combines several benefits as learning space on campus. The outstanding benefits include 24-hour opening, technology-enabled facilities, supportive environment for design, and convenient location. Therefore, students choose Zone24 for their learning at night.

Zone24's space is conducive for inspiration of creative ideas and interactive learning through the projects and collaboration with other students, which is a significant trend in global curriculum reform for community college and other institutes of higher education (Lo, Chiu, \& Chu, 2013). Moreover, for those "night owls" students who prefer to work in nighttime environments, it is also important for libraries to better understand the learning habits of these students. As this research study has revealed, some students have higher concentration and potentially better productivity at night. A few respondents indicated to us the following points:

Student D: I prefer to do my homework at night. I like the silence.

Student D: I can concentrate more at night. There are fewer distractions such as WhatsApp messages.

Student E: I want to do our homework at daytime but it is difficult. I feel tired during the daytime.

Student D: Yes, I feel the submission deadline of our project is relatively tight at night. This feeling push me to do our project faster.

Student J: I usually have more ideas at night because of silence. 
Thus, Zone24 caters the needs of these individuals in terms of their night learning habits. As indicated in this study, daytime and night activities indicates that HKDI students consider Zone24 as a learning space for projects with collaborative learning style no matter daytime or nighttime. A study from Lo and Chiu (2015) finds that students often use HKDI Library for working on their assignments, which is similar to our respondents in this study on Zone24. These findings further represent that Zone24 is able to support students' learning.

Needs of Students at Night

Overall, Zone24 is an effective space to support collaborative learning and student projects at HKDI. Recreation and learning go hand in hand during evening and overnight periods at Zone24. The findings show that eating is a specific behavior at night in Zone24. Zone24 provides vending machines so that students can eat and drink when they are engaged in their night learning activities. Students do not need to spend time to go far away for eating. A relaxed learning atmosphere could be created for certain students when they work on their project with snacks and drinks. Therefore, Zone24 has offered certain support to fulfill students' eating and drinking needs at night. Since the demands on the vending machines may be higher at night in particular, further enhancements could be implemented as earlier suggested by students.

Study room and printing services are both specific needs at night as indicated by student respondents. Zone24 is an encouraging space that enables students to freely discuss and exchange ideas with their peers or group mates. Students learn collaboratively while fostering the development of critical thinking through discussion, clarification of ideas, and evaluation of others' ideas (Gokhale, 1995). Since some respondents reveal that they are more active at night, the 24-hour learning space could establish more study rooms for students to facilitate learning. Yet, budget is probably a challenge.

Printing service is an outstanding need many design students. Zone24 is supportive because students can print their works using the color all-in-one photocopier but the service can be further enhanced with more photocopiers. Sinclair (2007) suggests multiple options for printing output, such as color laser, poster, and plotters printing, can be provided in learning commons. Yet, this requires more space, budget, and technical support. 


\section{Conclusion and limitations}

As an effective learning space to support students' learning activities in the evenings and overnight, Zone24 allows for projects and collaborations as common activities. Our analysis of the specific activities and needs of students' nighttime activities is significant and allows librarians and administrators to better understand and enhance the service of a 24-hour opening learning space in order to better support and maximize learning effectiveness.

There are limitations of this study, however, in that interviews cover only HKDI students while the perspectives from other stakeholders such as staff are not included. Moreover, since most of the students are studying higher diploma programs for vocational training, the findings may have different results from 24-hour learning space or commons from the viewpoint of university students. In addition, as many students are studying design related disciplines, their user behaviors and needs may not be same as the students from other non-design disciplines. We are planning further studies involving a mix of questionnaire and interviews in order to further examine nighttime behaviors and needs analysis.

\section{References}

Bell, S. (2010). Project-Based Learning for the 21st Century: Skills for the Future. The Clearing House: A Journal of Educational Strategies, Issues and Ideas, 83(2), 39-43. doi:10.1080/00098650903505415

Bowman, A. C. (2013). 24-hour academic libraries: Adjusting to change.Journal of Access Services, 10(4), 217239.

Bennett, S. (2003). Libraries Designed for Learning. Washington, D.C.: Council on Library and Information Resources.

Donkai, S., Toshimori, A., \& Mizoue, C. (2011). Academic libraries as learning spaces in Japan: Toward the development of learning commons. The International Information \& Library Review, 43(4), 215-220. doi:10.1016/j.iilr.2011.10.003

Engel, D., Womack, K., \& Ellis, U. (2002). Opening a Library 24 Hours. Journal of Library Administration, 36(4), 95-108. doi:10.1300/J111v36n04_07

Gokhale, A. A. (1995). Collaborative Learning Enhances Critical Thinking. Journal of Technology Education, 7(1), 22-30.

HKDI. HKDI in the Spotlight. Retrieved from http://www.hkdi.edu.hk/?l=en\&s=1\&p=526 
Kwong, Z., Ho, E., Lam, P., \& Leung, S. (2011). Libraries as Learning Spaces - 2011 Study Summary Report. Working Paper 7. Hong Kong: Centre for Learning Enhancement And Research, The Chinese University of Hong Kong.

Lawrence, P., \& Weber, L. (2012). Midnight-2.00 am: what goes on at the library?. New Library World, 113(11/12), 528-548.

Lee, D., Huh, Y., \& Reigeluth, C. M. (2015). Collaboration, Intragroup Conflict, and Social Skills in Project-Based Learning. Instructional Science: An International Journal of the Learning Sciences, 43(5), 561-590. doi:10.1007/s11251-015-9348-7

Lippincott, J., \& Greenwell, S. (2011, 11 April 2011). 7 Things You Should Know About the Modern Learning Commons. ELI 7 Things You Should Know, EDUCAUSE Learning Initiative (ELI).

Lizabeth, A. W. (2004). What a difference a decade makes: transformation in academic library instruction. Reference Services Review, 32(4), 338-346. doi:10.1108/00907320410569680

Lo, P., \& Chiu, D. (2014). Graffiti Inside an Art and Design Library? The Hong Kong Design Institute Library Experience. 159, 40-48.

Lo, P., Chiu, D. K. W., \& Chu, W. (2013). Modeling Your College Library after a Commercial Bookstore? The Hong Kong Design Institute Library Experience. Community \& Junior College Libraries, 19(3-4), 59-76. doi:10.1080/02763915.2014.915186

Lo, P., \& Chu, W. (2015). Information for Inspiration: Understanding Information-Seeking Behaviour and Library Usage of Students at the Hong Kong Design Institute. Australian Academic \& Research Libraries, 46(2), 101-120. doi:10.1080/00048623.2015.1019604

McLeod, S. A. (2014). Maslow's Hierarchy of Needs. Retrieved from http://www.simplypsychology.org/maslow.html

Sewell, B. B. (2013). 24-hour access: Responding to students' need for late library hours at the University of Denver. Journal of Access Services, 10(1), 14-27.

Sinclair, B. (2007). Commons 2.0: Library Spaces Designed for Collaborative Learning. EDUCAUSE Quarterly, 4-6. 